\title{
A Unified Emergency Care System for the early management of emergencies in medicine.
}

\section{Lt Col D Morgan-Jones}

MBE, MRCGP, DMCC, RAMC

Chief Instructor

Defence Medical Services Training Centre, Keogh Barracks, Ash Vale, Aldershot, Hants GU12 5RQ.

e-mail: d.morgan-jones@virgin.net

\section{Lt Col TJ Hodgetts}

FRCP, FFAEM, DipIMC RCSEd, DipMedEd, RAMC

Consultant and Specialty Adviser in Accident \& Emergency,

MDHU Frimley Park Hospital, Portsmouth Road, Frimley, Surrey GU16 5UJ.

\section{Professor of Emergency Medicine and Trauma \\ University of Surrey \\ e-mail: tim.hodgetts@virgin.net}

SUMMARY: Emergency medicine is increasingly compartmentalised. The Unified Emergency Care System (UECS) requires the user to consider every option for emergency care for each patient, in a logical manner that transcends these artificial compartments and recognises the relative priority of concomitant medical, surgical, environmental and toxicological problems. The system is presented as a series of icons, allowing considerations to be made at a glance. Drop shadows refer the user to detailed management protocols for specific conditions. The system follows the logical sequence of quick history, quick look, primary survey with resuscitation and secondary survey. Established management principles of airwaybreathing-circulation-disability (ABCD) are incorporated. The complexity of the management algorithms increases from first aider through medic, paramedic, and primary care physician to emergency physician. The stepwise care facilitates seamless immediate medical care between providers, teamwork, and the development of a structured series of training programmes.

Introduction:

The problem

The work of the primary care practitioner and the emergency physician involves the treatment of a wide spectrum of acute life-threatening emergencies. The causes of these acute emergencies can be divided into three main categories (Fig 1).

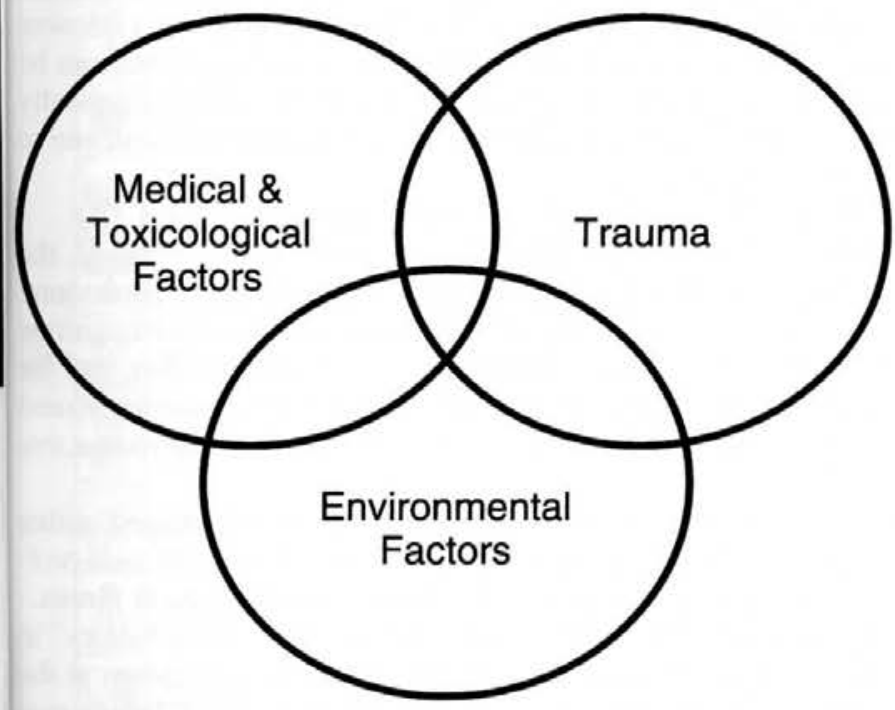

Fig 1. The Spectrum of Emergencies in Medicine

In some cases, pathology in more than one of these categories is involved-for example, the casualty from a road accident who is hypothermic; or the patient who has injuries from a fall, where the cause of the fall was a dysrhythmia or hypoglycaemia. Victims of serious injury can also be anticipated to have coexistent medical disease. Four case studies from Frimley Park Hospital illustrate these points (Table 1).
Table 1

Case histories illustrating acute concomitant medical and surgical pathology, and underlying medical disease in trauma patients.

\begin{tabular}{|c|l|}
\hline Case & History \\
\hline 1. & $\begin{array}{l}\text { A 24-year-old man presented in May 1998 following a } \\
\text { roll-over road traffic accident (RTA) in excess of 70 } \\
\text { mph. He was the passenger in the rear of a mini-van and } \\
\text { was seated in a wheelchair. He suffered from Duchenne } \\
\text { muscular dystrophy with nocturnal respiratory failure, } \\
\text { and wore a thoracic brace and leg splints. He did not } \\
\text { complain of any specific symptoms at the scene, but } \\
\text { was discovered to have multiple limb and pelvic } \\
\text { fractures, and an occipital infarct. }\end{array}$ \\
\hline 2. & $\begin{array}{l}\text { An 18-year-old man presented in September 1998 } \\
\text { following a 70 mph roll-over RTA. He was the driver of } \\
\text { the car and had been witnessed to have a fit prior to the } \\
\text { accident. He was not a known epileptic. }\end{array}$ \\
\hline 3. & $\begin{array}{l}\text { A 48-year-old man presented in September 1998 after a } \\
\text { road traffic accident at 50 mph. He was the driver, and } \\
\text { was known to be both an insulin-dependent diabetic and } \\
\text { an asthmatic on maintenance treatment. An episode of } \\
\text { hypoglycaemia had precipitated the accident. }\end{array}$ \\
\hline 4. & $\begin{array}{l}\text { A 61-year-old man presented in October 1998, having } \\
\text { been found collapsed and confused 'in a pool of blood' } \\
\text { inside a telephone box. The ambulance crew reported } \\
\text { he was hypotensive at the scene. After assessment in } \\
\text { accident and emergency it was evident he was an } \\
\text { epileptic who had been drinking heavily and had } \\
\text { omitted medication, had suffered a fit in the telephone } \\
\text { box and had lacerated his ankle in the fall. }\end{array}$ \\
\hline
\end{tabular}




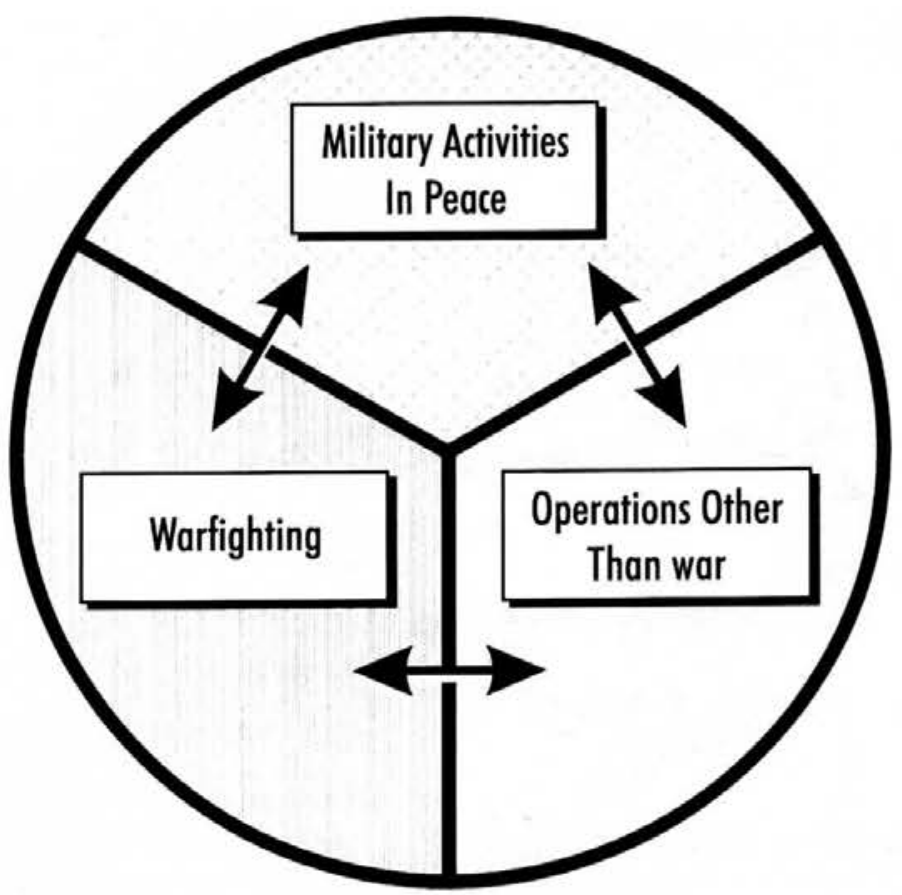

Fig 2. The Conflict Spectrum

In the military context the primary care practitioner (e.g., Regimental Medical Officer) and the emergency physician (e.g., A\&E doctor at the Field Hospital) will be exposed to an increasing number and severity of injured as the operational environment moves across the conflict spectrum (Fig 2)(1). The overlap between the categories of emergencies can be anticipated as above, yet may extend to include casualties unique to conflict situations such as those with multiple fragmentation wounds and nerve agent poisoning.

Despite this frequent overlap, current medical training increasingly compartmentalises the management of medical emergencies. Indeed, the need for a generic approach to resuscitation training in the undergraduate medical curriculum has been identified, which incorporates elements of the popular modular courses (2-4).

These modular courses are usually two or three days long and teach core knowledge and skills pertinent to a specific area of emergency medical practice. The first was the Advanced Cardiac Life Support (ACLS) course in 1972, with a curriculum specifically designed for the management of cardiac emergencies. This was followed in 1978 by the development of the Advanced Trauma Life Support (ATLS) course by the Lincoln Medical Education Foundation and the Southeast Nebraska Emergency Medical Services, for the early hospital management of the severely injured. The course was adopted by the American College of Surgeons in 1979, and is now international (5). The pre-hospital management principles of trauma derived from ATLS are encapsulated in the Pre-hospital Trauma Life Support (PHTLS) course (6). The early management of severe burns has become a victim of this process, with the development of Advanced Burns Life Support (ABLS), and within obstetrics Advanced Obstetric Life Support (AOLS) has been born. A separate course for medical emergencies, MEDIC-ALS, is currently under development.

Children too are dealt with separately, in the American Paediatric Advanced Life Support Course (PALS) (7) or the British Advanced Paediatric Life Support (APLS) (8) course.

This logic has not escaped the military. In 1986 the British Army adapted the ATLS course for field use as Battlefield Advanced Trauma Life Support (BATLS) (9). In the mid-1990's the Hazardous Chemical Advanced Life Support (HAZCHEM
ALS) course was developed by the Defence NBC Centre. This is a structured system for the management of casualties resulting from exposure to chemical warfare agents and industrial chemicals (10).

The benefit of the structured approach of these courses to the management of specific medical problems is not disputed. There is evidence that ATLS has improved confidence, communication and organisation of management of the seriously injured patient (11-13). There is limited evidence that it has improved outcome, when introduced into a developing trauma system in Trinidad and Tobago (14). The introduction of PHTLS training into the same system has been shown to significantly increase the incidence of pre-hospital interventions which also coincides with an additional improved outcome (15).

What is disputed is the ability of an individual to effectively run what is analogous to more than one mental computer programme at the same time for the same patient. These systems are not designed with any identifiable cross-links, and it is likely that where there is a mixture of trauma and/or medical and/or toxicological and/or environmental problems, that these will be dealt with in series rather than in parallel. Of course, this is the essence of emergency medicine and it would be hoped, but cannot be presumed, that the experienced emergency physician would be able to cope with this.

\section{The Solution}

The UECS provides a single, systematic "all hazard" approach to the management of acute emergencies in medicine. This is irrespective of whether they are trauma, medical, toxicological of environmental in nature. The Airway, Breathing, Circulatior $(A B C)$ approach is used to provide effective acute care in eact situation.

This UECS builds on the fundamental lessons instilled in al health care professionals-take a history, examine the patien establish a working diagnosis, then act. Whether it is myocardial infarct, multi-system trauma, or organophosphat poisoning the same approach is taken. The UECS is not to b regarded as a prescriptive protocol, but rather as a ment structure for the health care professional to manage the patien In particular, for those who deal with emergencies on a freque basis it provides a scaffold upon which their experience can b maximised. On the other hand, for those who deal infrequent with acutely ill patients it provides a comprehensive structure adhere to.

The UECS concept follows the logical steps of (Figs 3,4):

- Safety. This follows the 1-2-3 of safety (16) - yourself, th scene and the casualty. Personal safety remains paramoun Along with the normal protective measures there is recognitio for the need for full respiratory and skin protection, and fo casualty decontamination when dealing with casualties injure and/or contaminated with hazardous chemicals or radioactiv material.

- Quick History. Taking a short history is encouraged, eithe from the patient, relative, bystander or other health care prof essionals. This can give vital clues to occult injury or illness.

- Quick Look. The "quick look" follows the "quick history" i this system. In reality this would often be undertaken at th same time. It takes into account the fact that a health car professional will start to assess a patient as he moves toward him. What was previously a subconscious act is no formalised. The patient is scanned with special attention bein paid to the eyes (pupil size and reaction), skin colou secretions and respiratory rate. The "quick look" provides rapid assessment of the neurological status of the patient, an can provide key diagnostic indicators that may lead to the rapi and appropriate treatment of, for example, specific poisons. 


\section{Patient Assessment}

I. Safety

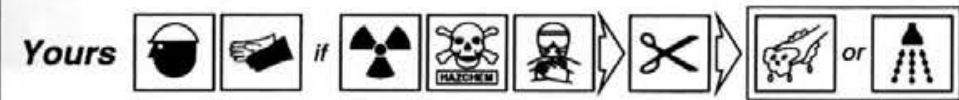

The Scene, The Casualty

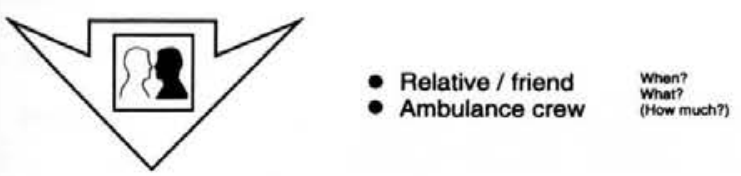

Quick History

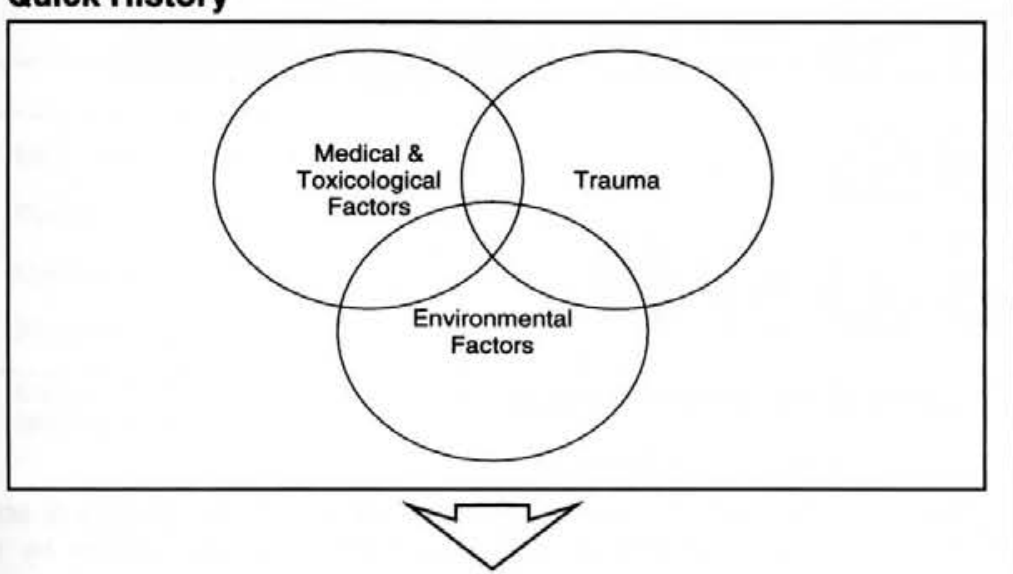

\section{Quick Look}

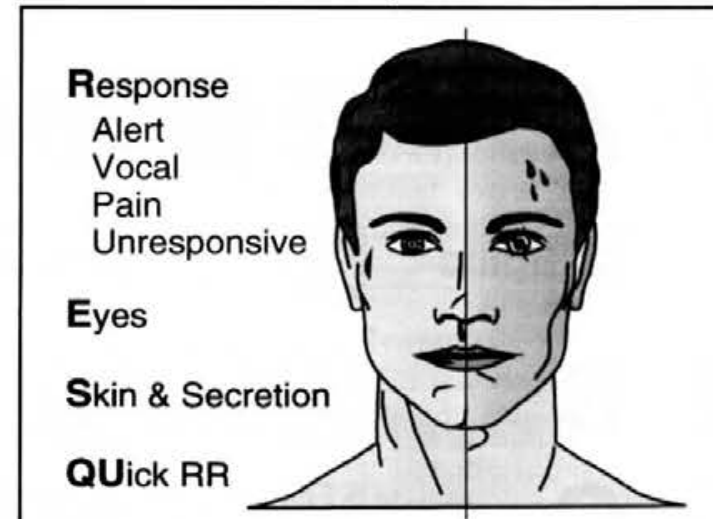

Fig 3. Patient Assessment

\section{Icon Glossary}

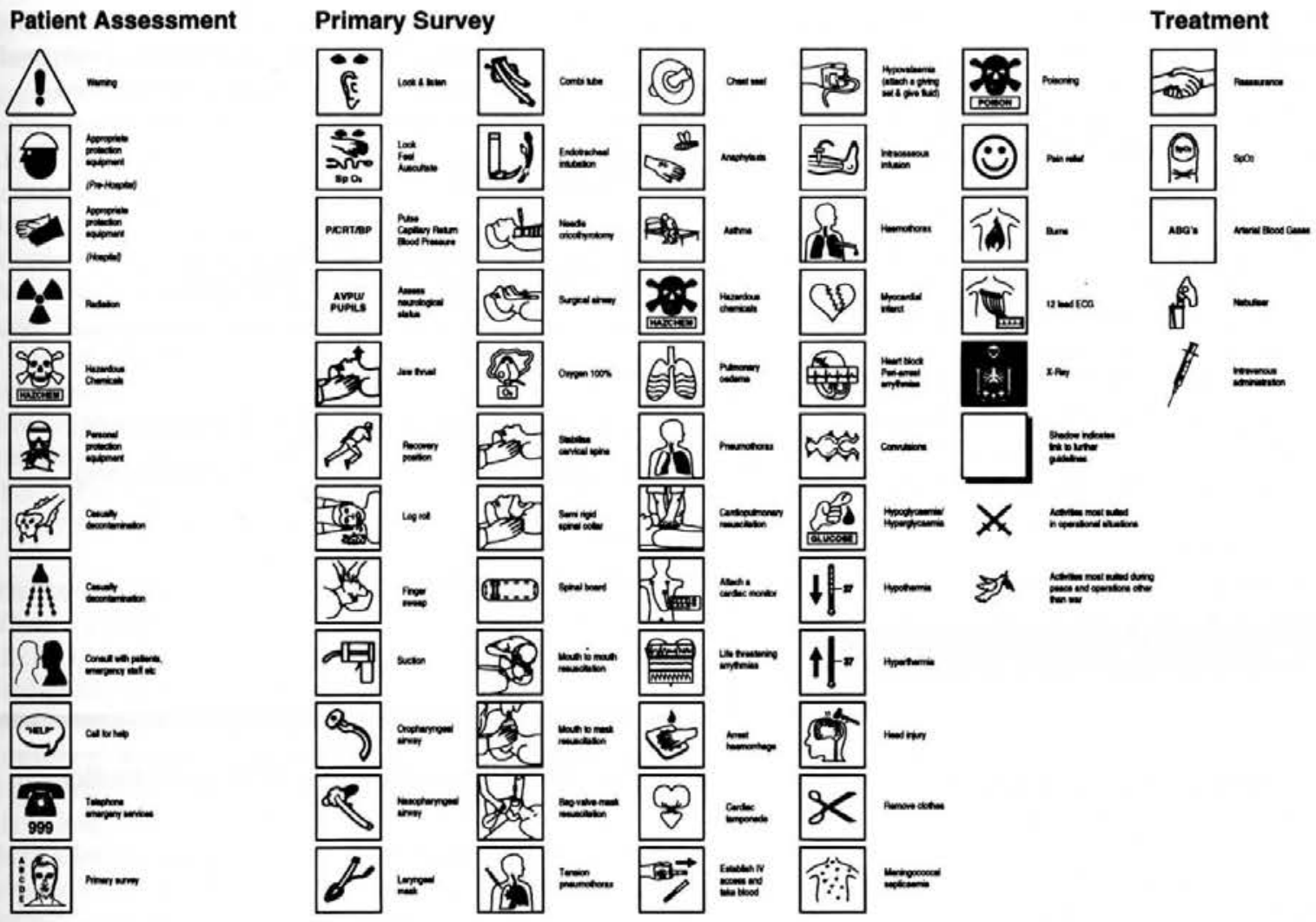

Fig 4. The Icon Glossary 
圆 Emergency Physician

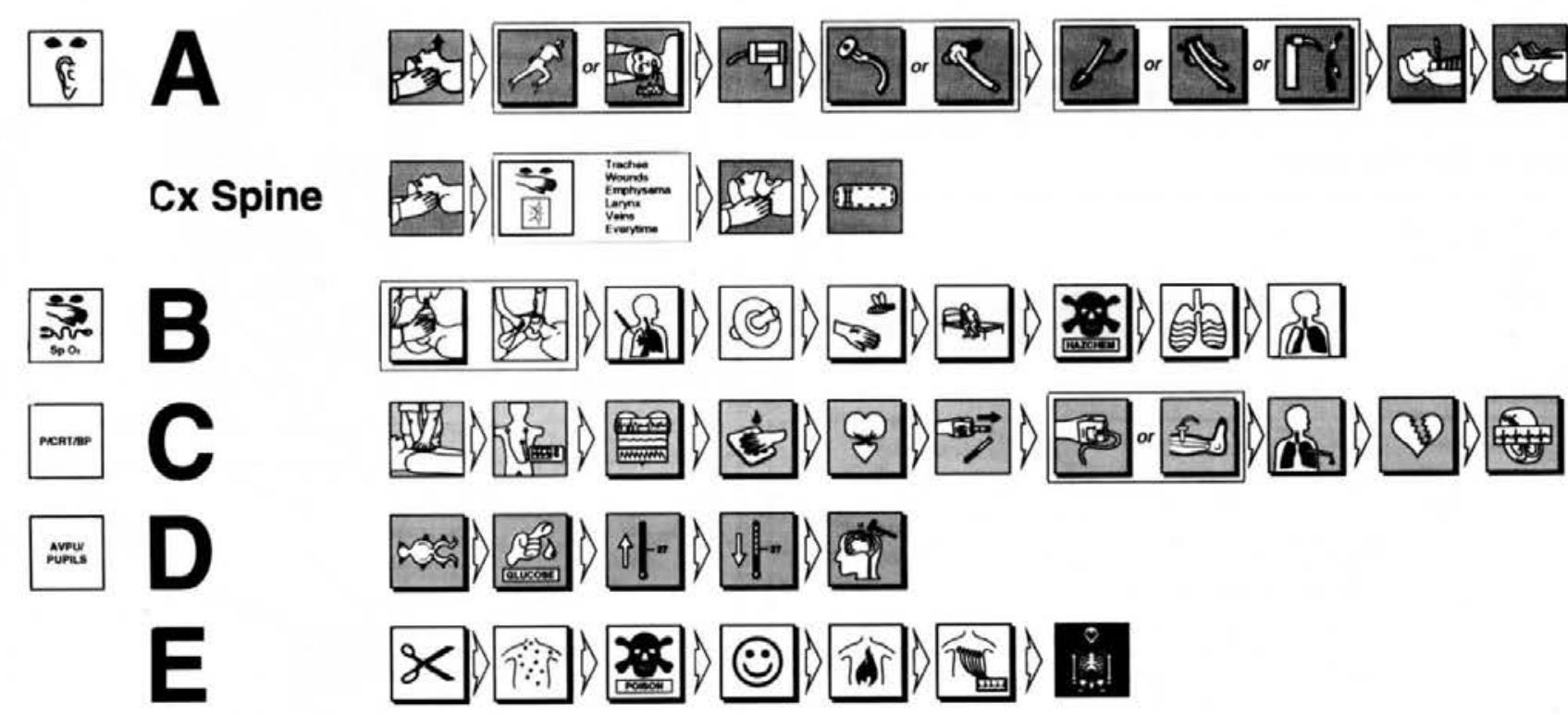

Fig 5. The Primary Survey: Emergency Physician

For the majority of patients the primary survey and appropriate resuscitation will follow this rapid overview. For patients who have been poisoned by hazardous chemicals a differential diagnosis is required to help identify if the poisoning is one of the few for which a specific antidote exists.

Figure 5 shows the "primary survey", which encompasses the established principles of assessing the ABCD coupled with the implementation of life-saving techniques. The techniques progress in complexity from left to right on the page. All options should be briefly considered so that the appropriate management is triggered. Exposure of the patient heralds the "secondary survey", which is a head to toe examination to identify all other pathology. This is limited in the pre-hospital setting by time and practicality. During the secondary survey all aspects of acute care are considered.

The system supports both a "vertical" approach by one clinician (starting at the top and moving to the bottom of the page, whilst working left to right across the icons) and a "horizontal" approach. The horizontal approach may be applied by a well trained emergency care team who will have individuals responsible for each of the A, B, C, D \& E components-and therefore can manage them simultaneously.

When the patient is handed over to the next level of care a simple mnemonic is followed for injury or illness, Table 2.

Table 2

Patient hand-over mnemonic

\section{Patient Hand-over}

\begin{tabular}{|ll|}
\hline \multicolumn{2}{|c|}{ Patient Hand-over } \\
\hline M & Mechanism of injury/Medical history \\
I & Injuries found? Illness known \& suspected \\
S & Signs \\
T & Treatment given \\
\hline
\end{tabular}

\section{A Stepwise approach}

The icon series comprehensively covers all aspects of acut medical care to the advanced level of intervention by th emergency physician. This approach is intended to b applicable by all levels of immediate medical care provider from first aider through medic, paramedic, pre-hospital docto and emergency physician. The level of complexity 0 intervention will progressively increase with each group, bu the UECS can be used by all.

An example of this can be seen in Figures $6 \mathrm{a}$ and $7 \mathrm{a}$ (theW Ey I paramedic interventions for asthma and burns), compared to $\overrightarrow{\text { Phe }}$ Figs $6 \mathrm{~b}$ and $7 \mathrm{~b}$ (the emergency physician interventions). ems

\section{Asthma}
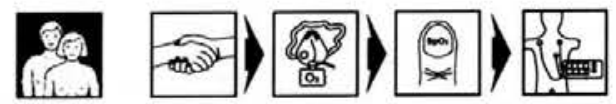

-tra部ce meraic: coorger prowle

Ig or bot: $\mathrm{si}$ is

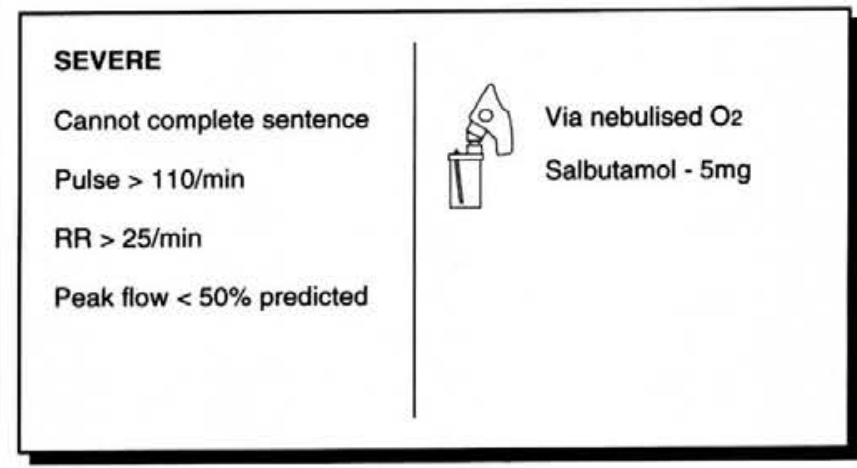

Fig 6a. Asthma protocol, adult (paramedic) andirmi based :

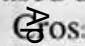

identififi

furpher toung-s

W

Evixlen

\$he: guig్geli inc藏ic nosita ind\$itra andōthe skifo tc without in ofal ventilat inc. p 


\section{Asthma}
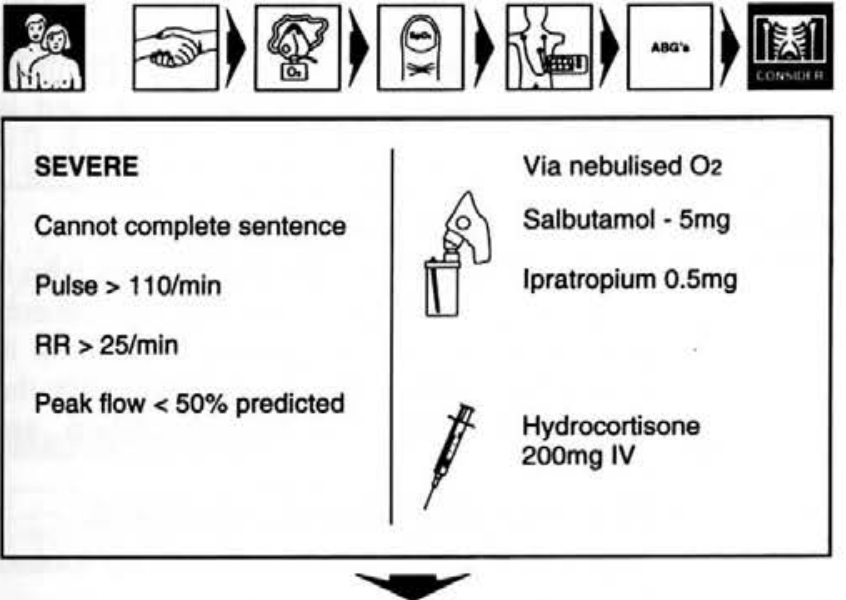

\section{LIFE THREATENING}

Cyanosis, Exhaustion

Silent ches

Peak flow $<33 \%$ predicted

Carbon dioxide normal or raised on blood gases

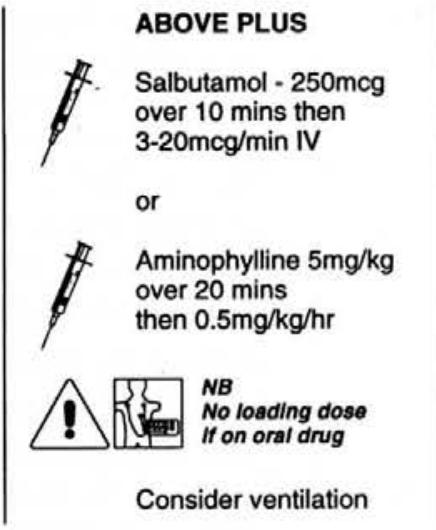

Consider ventilation

Fig 6b. Asthma protocol, adult (emergency physician)

\section{the Why Icons?}

to The UECS requires the user to consider every option for emergency care for each patient, in a logical manner that transcends the artificial compartments of current emergency medical practice, and recognises the relative priority of concomitant medical, surgical, environmental and toxicological problems in the same patient.

In order to do this safely and effectively, the system must be both simple and rapid. For this reason a series of unique icons is used. Such pictorial systems are familiar to computer users, and military map marking symbols are another accepted iconbased approach.

Cross-referencing to detailed management of a condition is identified by a drop shadow around the icon. This indicates a further book page. Equally, this system is ideally suited to touch-screen computer technology.

\section{Evidence-based practice}

Where evidence is available to support management guidelines, the best evidence is incorporated. An example is the inclusion of alternative advanced airway adjuncts in the prehospital and hospital settings. Recommended options to endotracheal intubation are the Laryngeal Mask Airway (LMA) and the Combitube (17). Both have been shown to be simpler skills to learn than intubation $(18,19)$, and both can be inserted without a laryngoscope with minimal movement of the head. In an evaluation of 470 patients comparing the devices, successful ventilation was more consistently achieved with the Combitube and paramedical personnel consistently preferred the
Combitube (20). Success in securing the airway has been repeatedly reported with the Combitube where intubation has failed (21-23). For this reason the Combitube icon appears on the pre-hospital algorithms.

More than $50 \%$ of surgical procedures are currently undertaken using an LMA (18). There is considerable opportunity for in-hospital training with this device. Nurses have been shown to utilise this airway effectively in the early management of in-hospital cardiac arrest (24). For these reasons the LMA icon (and the Combitube icon) appears on the hospital algorithms.

\section{A Worked Example-Medical+Trauma}

In this worked example the UECS will be applied in the prehospital and the emergency department environments.

\section{(i) Pre-hospital actions}

The Ambulance Service is called to a man whom the Fire Service has rescued from the ground floor of a house fire. Actions in this environment are often 'vertical', with one action being completed before the next is started.

\begin{tabular}{|c|c|}
\hline Actions & Detail \\
\hline Safety & $\begin{array}{l}\text { It is a Fire Service responsibility to remove the } \\
\text { casualty from the burning building to a place } \\
\text { of safety where treatment can start. } \\
\text { - Ambulance personnel will wear appropriate } \\
\text { protective equipment, to include latex gloves. }\end{array}$ \\
\hline $\begin{array}{l}\text { Quick } \\
\text { history }\end{array}$ & $\begin{array}{l}\text { From the Fire Service: } \\
\text { When? The casualty has just been rescued from } \\
\text { the building. } \\
\text { What? The casualty says he could not see in the } \\
\text { smoke and fell downstairs. He can't } \\
\text { walk, and he's got difficulty breathing. } \\
\text { The Fire Service have poured some cold } \\
\text { water over the burns on his arms and } \\
\text { legs. }\end{array}$ \\
\hline $\begin{array}{l}\text { Quick } \\
\text { look }\end{array}$ & $\begin{array}{l}\text { The casualty is wearing a towelling dressing } \\
\text { gown. He can answer questions appropriately. He } \\
\text { has burns and soot on his face. He is coughing } \\
\text { and is short of breath, with a raised respiratory } \\
\text { rate. Burns are apparent on the forearms and the } \\
\text { legs. }\end{array}$ \\
\hline $\begin{array}{l}\text { Primary } \\
\text { survey }\end{array}$ & $\begin{array}{l}\text { The primary survey page is followed. } \\
\text { - The head is manually immobilised. } \\
\text { - Signs of an upper airway burn are identified } \\
\text { (burn in mouth; singed nasal hairs). } \\
\text { - High concentration oxygen is given. } \\
\text { - Neck examination is normal before a semi- } \\
\text { rigid cervical collar is applied. The decision is } \\
\text { taken to evacuate the patient on a long spinal } \\
\text { board. } \\
\text { The chest is observed and auscultated. There is } \\
\text { no sign of a [tension] pneumothorax. } \\
\text { Widespread wheezing is heard. The paramedic } \\
\text { asks, "Are you asthmatic?" and the patient } \\
\text { replies that he is (Fig 6a). Oxygen is changed } \\
\text { for a } 5 \mathrm{mg} \text { salbutamol nebuliser. A pulse } \\
\text { oximeter is attached, which reads } 97 \% \text {. }\end{array}$ \\
\hline
\end{tabular}




\begin{tabular}{|l|l|}
\hline Actions & Detail \\
\hline $\begin{array}{l}\text { Primary } \\
\text { survey }\end{array}$ & $\begin{array}{l}\text { - The paramedic decides to attach the patient } \\
\text { to the ECG monitor when he is moved to the } \\
\text { ambulance. Intravenous access is established } \\
\text { in the right antecubital fossa, and 1 litre of } \\
\text { Hartmann's solution started. There is no } \\
\text { protocol for taking blood in this particular } \\
\text { service. }\end{array}$ \\
& $\begin{array}{l}\text { The patient remains alert. The paramedic is } \\
\text { conscious that the patient may become } \\
\text { hypothermic having been covered in cold } \\
\text { water. } \\
\text { - A rapid assessment for other injuries reveals a } \\
\text { fractured left tibia. This is splinted in a box } \\
\text { splint. } \\
\text { On route to the hospital the paramedic applies } \\
\text { strips of Clingfilm to dress the burns (Fig 7a), } \\
\text { and covers the patient with a blanket. }\end{array}$ \\
\hline
\end{tabular}

\section{(ii) Hospital actions}

Actions in this environment are often 'horizontal', with concomitant assessment of the airway, breathing and circulation. For example, one doctor will be obtaining intravenous access, taking blood for investigation and starting an intravenous infusion at the same time as another is assessing and managing the airway. This should be taken into consideration when reading the list of action details below.

\begin{tabular}{|c|c|}
\hline Actions & Detail \\
\hline Safety & $\begin{array}{l}\text { The assembled team will wear protective } \\
\text { equipment against: } \\
\text { - Patient's blood (latex gloves }+/ \text { - eye } \\
\text { protection) } \\
\text { - Radiation from X-rays (lead gown) }\end{array}$ \\
\hline $\begin{array}{l}\text { Quick } \\
\text { history }\end{array}$ & $\begin{array}{l}\text { From the ambulance attendant as the patient is } \\
\text { brought into the resuscitation room, to include: } \\
\text { - Mechanism of injury } \\
\text { Upstairs in a house fire; smoke }+++ \text {; fell } \\
\text { downstairs } \\
\text { - Injuries found and suspected } \\
\text { Burns to face and upper airway } \\
\text { Burns to arms and legs } \\
\text { Broken left tibia } \\
\text { Known asthmatic patient } \\
\text { - Signs (pulse, respiratory rate, blood pressure, } \\
\text { SpO2) } \\
\text { PII0; RR30; SpO } 299 \text {; BP not taken } \\
\text { Treatment given } \\
\text { Oxygen; } 5 \text { mg salbutamol nebuliser; spinal } \\
\text { immobilisation; box splint to lower left leg; } \\
\text { Clingfilm to arm and leg burns }\end{array}$ \\
\hline
\end{tabular}

\begin{tabular}{|l|l|}
\hline Actions & Detail \\
\hline Quick & $\begin{array}{l}\text { The patient is alert and talking, but is unable to } \\
\text { look } \\
\text { around his mouth, and has singeing of his nasal } \\
\text { hairs. He has a raised respiratory rate and is } \\
\text { wheezing. }\end{array}$ \\
\hline $\begin{array}{l}\text { Primary } \\
\text { survey }\end{array}$ & $\begin{array}{l}\text { The primary survey page is followed. } \\
\text { - In view of the signs of an upper airway burn it } \\
\text { is decided to electively intubate the patient. } \\
\text { High concentration oxygen by face mask is } \\
\text { given. The primary survey continues while the } \\
\text { drugs for rapid sequence induction are } \\
\text { prepared. } \\
\text { - Full spinal immobilisation is continued. } \\
\text { - Signs of a tension pneumothorax are looked } \\
\text { for. } \\
\text { - In view of the continuing respiratory distress } \\
\text { and widespread wheeze 5mg salbutamol } \\
\text { nebuliser is repeated and 200mg hydro- } \\
\text { cortisone given intravenously (Fig 6b). } \\
\text { - The patient is monitored by ECG, pulse } \\
\text { oximetry and non-invasive blood pressure. } \\
\text { - Blood is taken for full blood count, U\&E and } \\
\text { cross-match 4 units (polytrauma). } \\
\text { - Intravenous crystalloid is continued. } \\
\text { The patient is kept warm. } \\
\text { - Full exposure in stages is undertaken to } \\
\text { establish the size and depth of the burns (Fig } \\
\text { 7b); a reminder is given to take blood for } \\
\text { carboxyhaemoglobin, if not already done; } \\
\text { Clingfilm is retained as the dressing. } \\
\text { Maintenance fluid requirements are calculated } \\
\text { for the burn. Other injuries are excluded. } \\
\text { - Intravenous morphine is given for pain. } \\
\text { - Primary survey X-rays are taken (which may } \\
\text { be taken during the } 1^{0} \text { survey rather than at the } \\
\text { end), and the injured limb is X-rayed. }\end{array}$ \\
\hline
\end{tabular}

\section{Conclusion}

The UECS builds on the systematic approach to th management of acutely ill or injured patients followin: established guidelines. Uniquely, it provides a single, flexibl system for the spectrum of acute life-threatening emergencies The need for a generic approach to resuscitation training fo undergraduate medical students has been recognised (2-4). Th UECS meets this requirement and extends it to all immediat care providers, offering a rational, stepwise approach t training for the first aider, medic, paramedic, primary car physician, and emergency physician. This facilitates teamwor and seamless continuity of care.

Icons have been used to present the entire managemer system at a glance. A cross-reference to a detailed individua management protocol is identified by a drop shadow behind a icon. This system is suitable to enable production of a rapi reference aide memoire, or for use in computer touch scree technology.

\section{Acknowledgement}

We would like to thank Mr Mike Hitchen of the Graphic Department Defence NBC Centre and Mr Richard Butlet 


\section{Burns}

\section{Associated problems}

- Associated injuries are common

Early intubation is required for signs of airway burn: transport rapidly to hospital

1. Hypothermia is likely if excessive water is used for cooling burns

\section{Management}

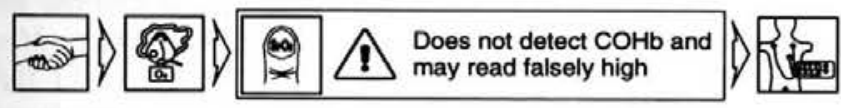

\section{Treatment}

- Burns dressings:

- Cold water useful in first 10 mins following burn: beware hypothermia

- Clingfilm strips for large burns

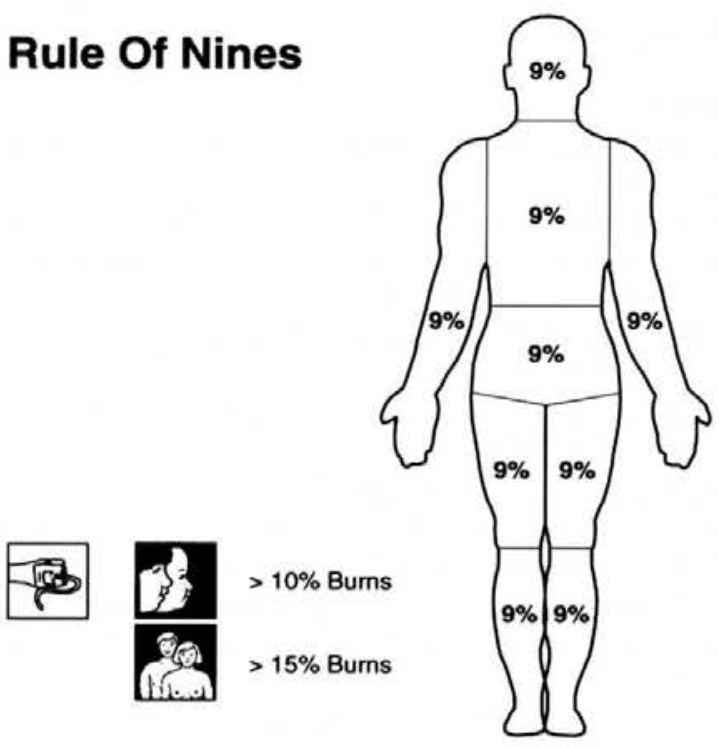

Replace fluid using the following formulae:

$4 \times$ weight $(\mathrm{kg}) \times \%$ burn $=$ mls of HARTMAN'S ONLY in 24 hours

GIVE HALF in the first EIGHT HOURS from the TIME OF BURN

\section{他}

Fig 7a. Burns protocol (paramedic)

\section{Burns}

\section{Associated problems}

- Associated injuries are common

- If signs of airway burn:

10. Consider early intubation.

Elective surgical airway (local anaesthetic) if general anaesthetic not possible

1. Hypothermia is likely if excessive water is used d. for cooling burns

\section{Management}

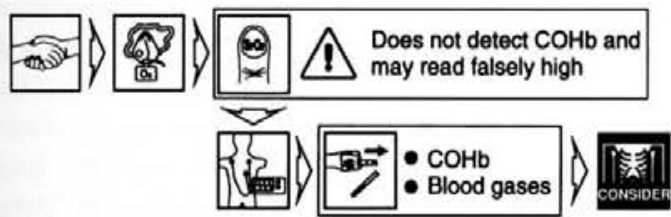

\section{Treatment}

\section{- Burns dressings:}

- Clingfilm strips for large burns

- Plastic bags with liquid paraffin

lubrication for hand burns

- Paraffin gauze for small burns

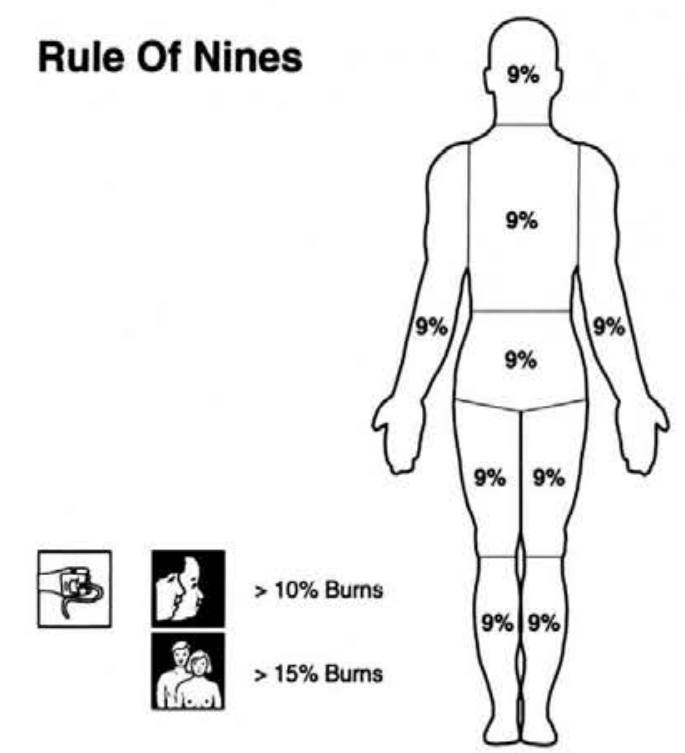

- Escharotomy for full thickness burns of:

- Chest - to improve ventilation

- Limbs - to restore circulation

Replace fluid using the following formulae:

$4 \times$ weight $(\mathrm{kg}) \times \%$ burn $=$ mls of HARTMAN'S ONLY in 24 hours

GIVE HALF in the first EIGHT HOURS from the TIME OF BURN

Fig 7b. Burns protocol (emergency physician) 
Graphics Department Defence Medical Services Training Centre for the considerable hard work which has gone into preparing the diagrams.

\section{REFERENCES}

1. Ministry of Defence. The Application of Force. Army Code NO 71622, 1998.

2. Carveth SW, Burnap TK, Betchel J, Mcintyre K, DONEGAN J, et al. Training in Advanced Cardiac Life Support. JAMA 1976; 235: 2311-2315.

3. Malins A, Symes J, TURner S. ATLS Training. Rescue \& Resuscitation 1998; 3:2.

4. Price A, Hughes G. Training in Advanced Trauma Life Support. BMJ 1998; 316: 878.

5. American College of Surgeons Committee on Trauma. Advanced Trauma Life Support Course for Physicians. Chicago: American College of Surgeons, 1989.

6. National Association of Emergency Medical Technicians. Pre-Hospital Trauma Life Support (3e). Chicago: Mosby Lifeline, 1994.

7. Chameides L, Hazinski M, eds. Pediatric Advanced Life Support. Dallas: American heart Association, 1997.

8. Advanced Life Support Group. Advanced Paediatric Life Support: the practical approach (2e). London: BMJ Publishing, 1996.

9. Army Medical Directorate. Battlefield Advanced Trauma Life Support. 1997, Army Code 63726.

10. Morgan-Jones D, Hodgetts T. The management of casualties of sarin gas attack. J Accid Emerg Med 1996; 13: 431-2.

11. Greenslade G, Taylor R. Advanced Trauma Life Support aboard RFA Argus. J R Nav Med Serv 1992; 78: 23.

12. Ali J, Howard M. The Advanced Trauma Life Support Course For Senior Medical Students. Can J Surg 1992; 35: 541.

13. Walsh D, Lammert G, Devoli J. The Effectiveness of the Advanced Trauma Life Support System in a Mass Casualty Situation by Non-Trauma Experienced Physicians: Grenada
1983. J Emerg Med 1989; 7: 175.

14. Ali J, AdAm R. Butler A, et al. Trauma outcome improves following the Advanced Trauma Life Support program in a developing country. J Trauma 1993; 34: 890.

15. Ali J, Adam R, Gana T, Bedaysie H, Williams J. Effect of the pre-Hospital Trauma Life Support program (PHTLS) on Pre-hospital trauma care. J Trauma 1997; 42: 786-790.

16. Advanced Life Support Group. Major Incident Medical Management and Support: the practical approach. London: BMJ Publishing, 1995.

17. Advanced Life Support Course Sub-Committee. Advanced Life Support Course Provider Manual (3e). London: Resuscitation Council (UK), 1998.

18. Sasada M, GabBotT D. The role of the laryngeal mask airway in pre-hospital care. Resuscitation 1994; 28: 97-102.

19. ATHERTON G, JohnSON J. Ability of paramedics to use the Combitube in pre-hospital cardiac arrest. Ann Emerg Med 1993; 22: 1263-1268.

20. RumBALl C, MACDONALD D. The PTL, laryngeal mask and oral airway: a randomized pre-hospital comparative study of ventilatory device effectiveness and cost effectiveness in 470 cases of cardiorespiratory arrest. Pre-hospital Emergency Care 1997; 1: 1-10.

21. Klauser R, Roggla G, Pidlich J, Leithner C, Frass M. Massive upper airway bleeding after thrombolytic therapy: successful airway management with the Combitube. Ann Emerg Med 1992: 21: 431-433.

22. Staudinger T, Tesinsky P, Klappacher G, Brugger S RINTELEN C, et al. Emergency intubation with the Combitube in two cases of difficult airway management. Eur J Anaesthesiol 1995; 12: 189-193.

23. Banyai M, Falger S, Roggla M, Brugger S, Staudinger $\mathrm{T}$, et al. Emergency intubation with the Combitube in a grossly obese patient with a bull neck. Resuscitation 1993; 26: 271-276.

24. Stone B, Leach A, Alexander C, Ruffer D, McBeth C et al. The use of the laryngeal mask airway by nurses during cardiopulmonary resuscitation. Anaesthesia 1994; 49: 3-7. 